\title{
Design of C-Band Microstrip Patch Antenna for Radar Applications Using IE3D
}

\author{
V.Harsha Ram Keerthi ${ }^{1,}$ Dr.Habibullah Khan ${ }^{2,}$ Dr.P.Srinivasulu ${ }^{3}$ \\ ${ }^{I}$ (M.Tech, Communication and Radar systems, ECE, K.L. University, India) \\ ${ }^{2}$ (Head of the ECE department, K.L. University, India) \\ ${ }^{3}$ (Scientist-SF, National Atmospheric Research Laboratory, Gadanki, India)
}

\begin{abstract}
In the recent years the development in communication systems requires the development of low cost, minimal weight and low profile antennas that are capable of maintaining high performance over a wide spectrum of frequencies. This technological trend has focused much effort into the design of a microstrip patch antenna. The objective of this paper is to design an microstrip line fed rectangular microstrip patch antenna which operates in C-band at 5GHz. Therefore, method of moments based IE3D software is used to design a Microstrip Patch Antenna with enhanced gain and bandwidth. IE3D is an integrated full-wave electromagnetic simulation and optimization package for the analysis and design of $3 D$ and planar microwave circuits, MMIC, RFIC, RFID, antennas, digital circuits and high speed Printed Circuit Board (PCB). The IE3D has become the most versatile, easy to use, efficient and accurate electromagnetic simulation tool. The length of the antenna is nearly half wavelength in the dielectric it is a very critical parameter, which governs the resonant frequency of the antenna. In view of design, selection of the patch width and length are the major parameters along with the feed line dimensions. Desired patch antenna design was simulated by IE3D simulator program. The entire project is being carried out at National Atmospheric Research Laboratory (NARL), ISRO.
\end{abstract}

Key words: C-Band, IE3D, Micro strip Patch, RADAR, Wind profiler

\section{Introduction}

In this paper the increment in Bandwidth and Gain of Rectangular Microstrip Patch antenna which operates at $5 \mathrm{GHz}$ has been discussed in details. Microstrip patch antenna has been received tremendous attention since the last two decades and now it becomes a major component in the development of Wind Profile Radar. Microstrip antenna is a printed type antenna consisting of a dielectric substrate sandwiched in between a ground plane and a patch.

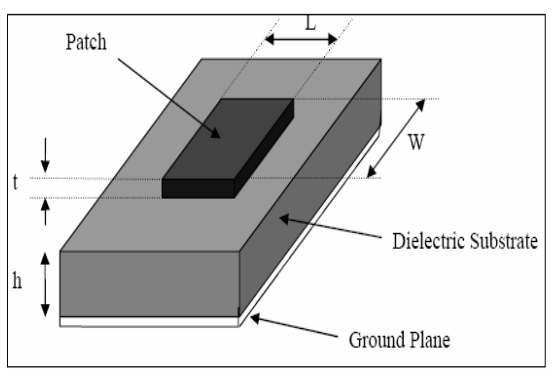

Fig1: A Typical Microstrip Patch Antenna

In this project Microstrip patch antenna technology is used for designing of the antenna suitable for WPR because of its commercial reality with applications in wide variety of microwave systems, Personnel communication system(PCS), wireless local area network (WLAN) etc. These are preferred over other types of radiators because of its low profile and light weight but its major drawback is its narrow bandwidth and low gain. This is one of the problems that researchers around the world have been trying to overcome. In this project, we have tried to increase the gain and bandwidth of the patch antenna. It has been noticed that there is some significant increments in bandwidth and gain measurements.

\section{Fundamental Specifications of Patch Antennas}

A micro strip or patch antenna is a low profile antenna that has a number of advantages over other antennas it is light weight, inexpensive, and easy to integrate with accompanying electronics. While the antenna can be 3D in structure (wrapped around an object, for example), the elements are usually flat hence their other name, planar antennas. 


\section{II.1 Impedance Matching}

Looking at the current (magnetic field) and voltage (electrical field) variation along the patch, the current is maximal at the center and minimal near the left and right edges, while the electrical field is zero in the center and maximal near the left and minimal near the right edges. The figures below clarify these quantities.

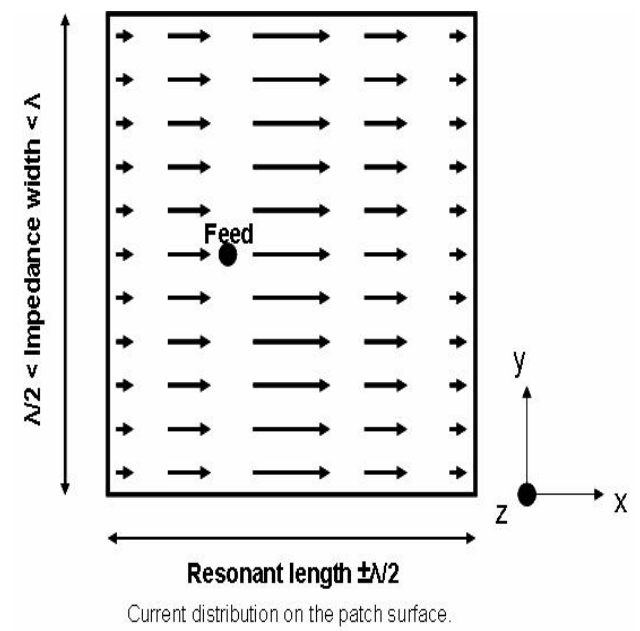

\section{II.2 Radiation Pattern}

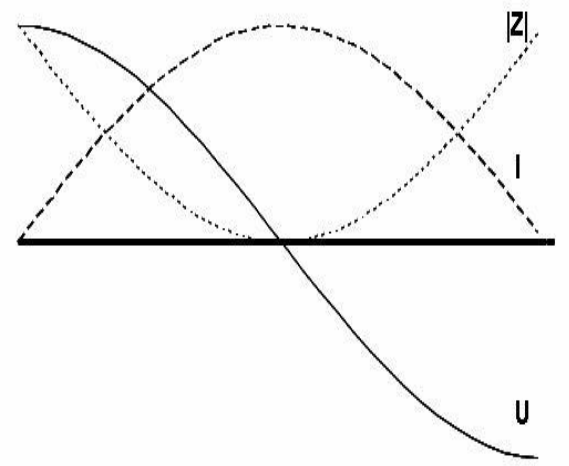

Voltage (U), current (I) and impedance (|Z|) distribution along the patch's resonant length

The patch's radiation at the fringing fields results in a certain far field radiation pattern. This radiation pattern shows that the antenna radiates more power in a certain direction than another direction. The antenna is said to have certain directivity. This is commonly expressed in $\mathrm{dB}$. The rectangular patch excited in its fundamental mode has a maximum directivity in the direction perpendicular to the patch (broadside). The directivity decreases when moving away from broadside towards lower elevations. The $3 \mathrm{~dB}$ beam width (or angular width) is twice the angle with respect to the angle of the maximum directivity, where this directivity has rolled off $3 \mathrm{~dB}$ with respect to the maximum directivity.

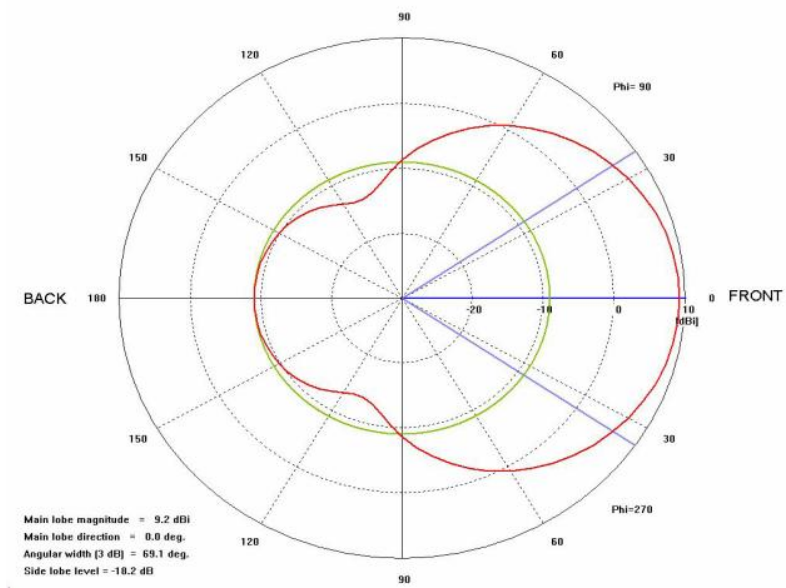




\section{II.3 Antenna Gain}

Antenna gain is defined as antenna directivity times a factor representing the radiation efficiency. This efficiency is defined as the ratio of the radiated power $(\mathrm{Pr})$ to the input power $(\mathrm{Pi})$. The input power is transformed into radiated power and surface wave power while a small portion is dissipated due to conductor and dielectric losses of the materials used. Surface waves are guided waves captured within the substrate and partially radiated and reflected back at the substrate edges. Surface waves are more easily excited when materials with higher dielectric constants and/or thicker materials are used. Surface waves are not excited when air dielectric is used. Antenna gain can also be specified using the total efficiency instead of the radiation efficiency only. This total efficiency is a combination of the radiation efficiency and efficiency linked to the impedance matching of the antenna.

\section{II.4 Impedance bandwidth/return loss bandwidth}

This is the frequency range wherein the structure has a usable bandwidth compared to a certain impedance, usually $50 \Omega$. The impedance bandwidth depends on a large number of parameters related to the patch antenna element itself (e.g., quality factor) and the type of feed used. The plot below shows the return loss of a patch antenna and indicates the return loss bandwidth at the desired (S11/VSWR). The bandwidth is typically limited to a few percent. This is the major disadvantage of basic patch antennas.

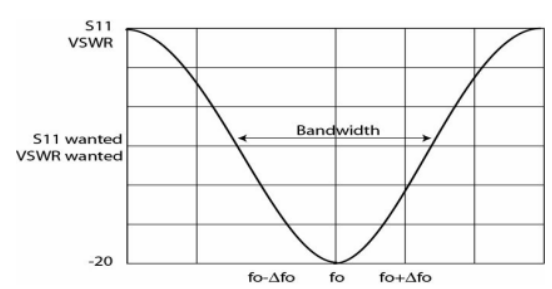

Another approach is to see the patch as a parallel RLC resonant circuit. This means a phase shift that changes versus frequency is present, as shown in the following plot:

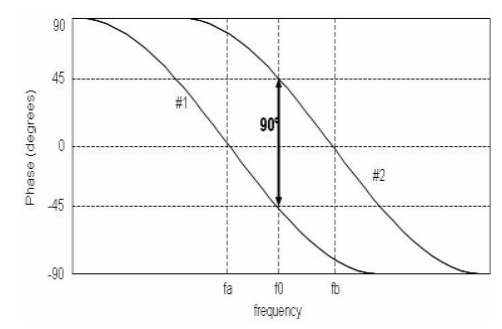

\section{Operation of Wind Profiler}

Wind profilers depend upon the scattering of electromagnetic energy by minor irregularities in the refractive index of air. The reflective index is a measure of the speed at which electromagnetic wave propagates through a medium. Atmosphere is the medium for wind profiling. A spatial variation in this index encountered by a radio wave causes a minute amount of energy to be scattered in all direction.

In this atmosphere, minor irregularities in the refractive index exist over a wide range of sizes in the troposphere and stratosphere. The refractive index depends primarily on the temperature, pressure and humidity of the air. The radar depends on the scattering of EM wave energy of the air associated with clear air turbulence (CAT). The atmosphere minor irregularities in the index refraction exist over a wide range of refraction sizes.

The wind, as it varies in direction or speed produce turbulent eddies(small whirling currents of air). The turbulent eddies are created over a spectrum of sizes ranging from many tens of metres down to centimetres.

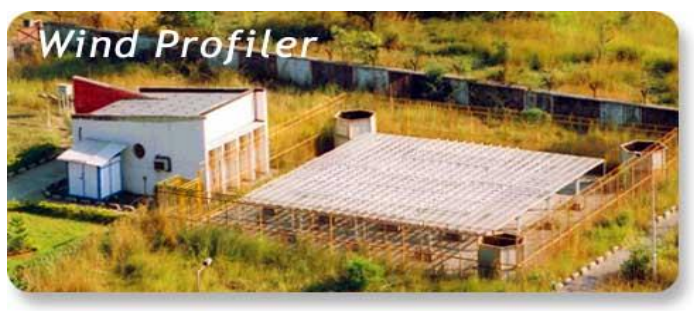

Wind profiler radars are vertically directed pulsed Doppler radars capable of analysing the back-scattered signals to determine the velocity of air along the beams. By steering the beams typically $15^{\circ}$ from zenith, the horizontal and vertical components of the air motion can be obtained. 
Radar systems for weather forecasting purposes are to be accommodated in the frequency allocations of the radiolocation service and/or the meteorological aids service. Existing uses in these bands need to be protected and compatibility with the services in the adjacent bands has to be assured. On the other hand, accommodation in the frequency bands of other radio services could be considered, if this is acceptable from a frequencysharing point of view.

For the identification of the various compatibility and/or sharing options, a clear understanding of the concept of wind profiler radar systems and their behaviour in the electromagnetic environment is needed.

The important applications of a conventional Wind Profile Radar lies in (i) Short range forecasting, (ii) Convective storm initiation, (iii) Climates, (iv) Air Pollution, (v) Aviation operations and flight planning, and (vi) Rocket and missile launching etc.

\section{Overview of IE3D Software}

IE3D is a full wave, method of moments (MOM) based electromagnetic simulator for analyzing and optimizing planar and 3D structures in a multi-layer dielectric environment. It solves Maxwell's equation in integral form and its solutions include the wave effects, discontinuity effects, coupling effects and radiation effects. The simulated result includes S,Y, and Z-parameters, VSWR, RLC equivalent circuits, current field distribution, near and far field estimation, radiation pattern etc.

IE3D is an extremely useful tool in the design of MMICs, RFICs, RF printed circuits, Micro strip and wired RF Antennas, multilayer PCBs and IC interconnections.

\section{IV.1 The important features of Zeland Software, Inc. IE3D Version 12:}

(a) IE3D Fast EM Design Kit for real-time full-wave EM tuning, optimization and synthesis.

(b) Multi-fold speed improvement and multi-CPU support for much improved efficiency.

(c) Equation-based schematic-layout editor with Boolean operations for easy and flexible geometry editing and parameterization.

(d) Lumped element equivalent circuit automatic extraction and optimization for convenient circuit designs.

(e) Improved integration into Microwave Office from Applied Wave Research.

\section{IV.2 Applications of IE3D:}

(a) RF circuits, LTCC circuits and RF ICs.

(b) Microwave, RF and wireless antennas.

(c) RFID tag antennas.

(d) HTS filters.

(e) Electronic packaging and signal integrity.

(f) Microwave circuits and MMICs.

(g) Many other low to high frequency structures.

\section{IV.3 Applications of IE3D in Antennas:}

(a) Planar antennas such as micro strip antennas and slot antennas.

(b) Wire antennas such as various types of dipole, monopole, helix and quadrifilar antennas.

(c) Small antennas such as inverted-F antennas and its derivations.

(d) Dielectric resonator antennas.

(e) RFID antennas.

(f) Optical frequency antennas.

(g) Many other types of antennas.

\section{Design of a Rectangular Micro strip Patch Antenna}

In this paper, selected parameters are: Resonant Frequency $=5 \mathrm{GHz}(\mathrm{C}$ band), Dielectric material is RT-DUROID5880, Dielectric constant $\epsilon_{\mathrm{r}}=2.2$, Height of the dielectric substrate $\mathrm{h}=3.172 \mathrm{~mm}$. The dimension of the Rectangular Patch is given $600 \times 480$ mils, $\tan \partial=0.0004$ 


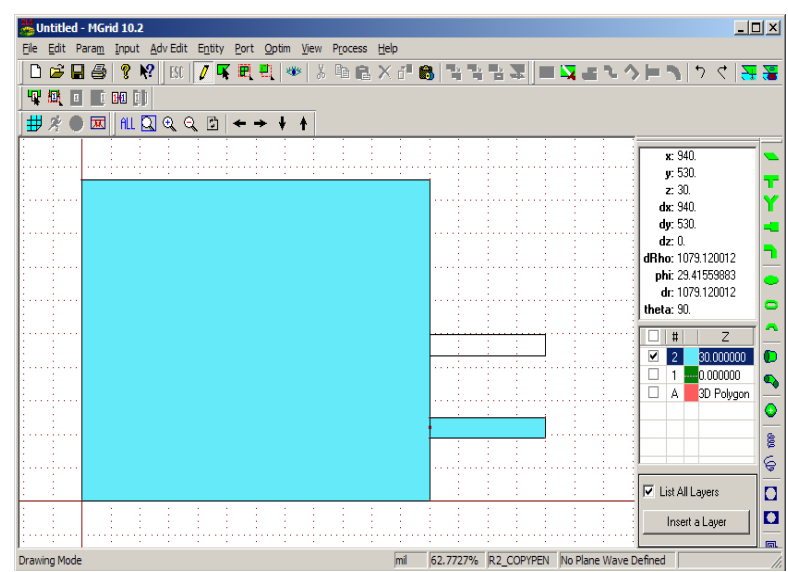

Automatic Edge Cell (AEC) enabled and Edge Cell Width $=6$ mils. MGRID will show the AEC Width vs. Regular Size $=9.6 \%$. Fmax $=10 \mathrm{GHz}, \mathrm{N}$ cells $=15 \mathrm{cells} / \lambda$.

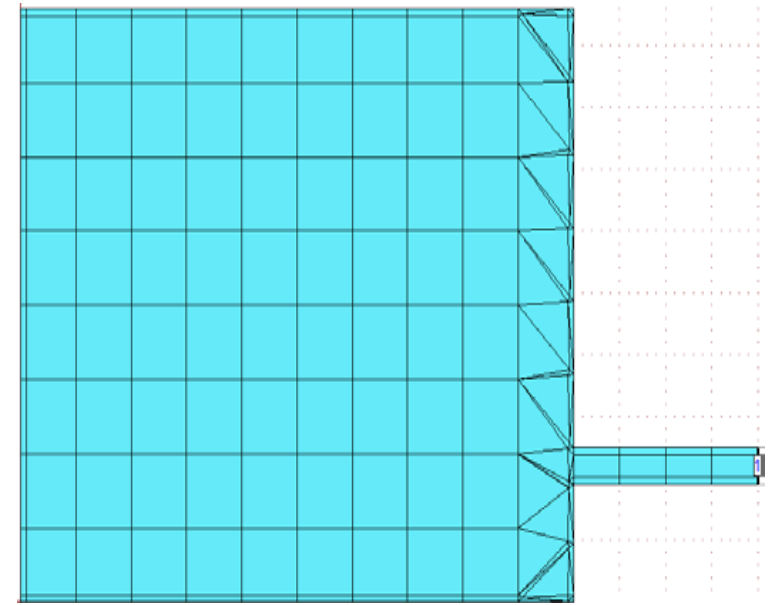

Fig.2: Meshed structure

\begin{tabular}{|c|c|c|}
\hline Automatic Meshing Parameters & & \\
\hline Basic Parameters & \multirow{5}{*}{ - Geomety Information- } & Cancel \\
\hline Highes Frequency (GHz): & & \\
\hline Cells per Wavelenghth 15 & & \\
\hline Estimated Max Cell Size 62.2455 & & \\
\hline -Optional Pramelers- & & 2 \\
\hline V A Automatic Edge Cells With 6 & 20/30 Area Ratio: & 100:0 \\
\hline$A E C$ Widh vs: Regular Size $9.6 \%$ & Min Sufface Cells: & 77 \\
\hline$\Gamma$ Meshing Oppimization & Min Surface Cells (AEC): & 119 \\
\hline Warning Limit 4000 & 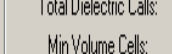 & $\frac{0}{0}$ \\
\hline -Simulation Parmemeters- & Min Volume Cells (AEC): & 0 \\
\hline$2 0 \longdiv { \text { For Áccuracy } }$ & Min Total Cells: & 77 \\
\hline $\begin{array}{l}\text { Display Options - } \\
\nabla \text { Keep Meshing }\end{array}$ & $\begin{array}{c}\text { Min Total Cells (AEC): } \\
\text { Max. Cell Size: }\end{array}$ & $\frac{119}{62.208}$ \\
\hline
\end{tabular}

Fig.3: MGRID Box 
VI. Simulated Result for Different Parameters

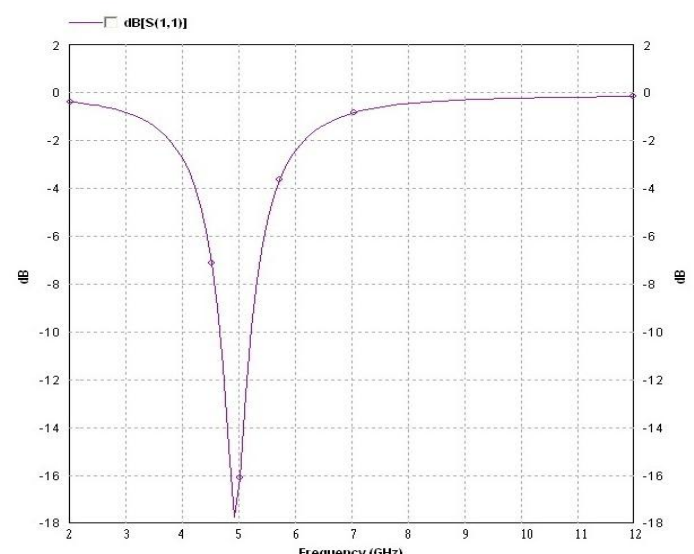

Fig. 4: Return Loss vs frequency plot

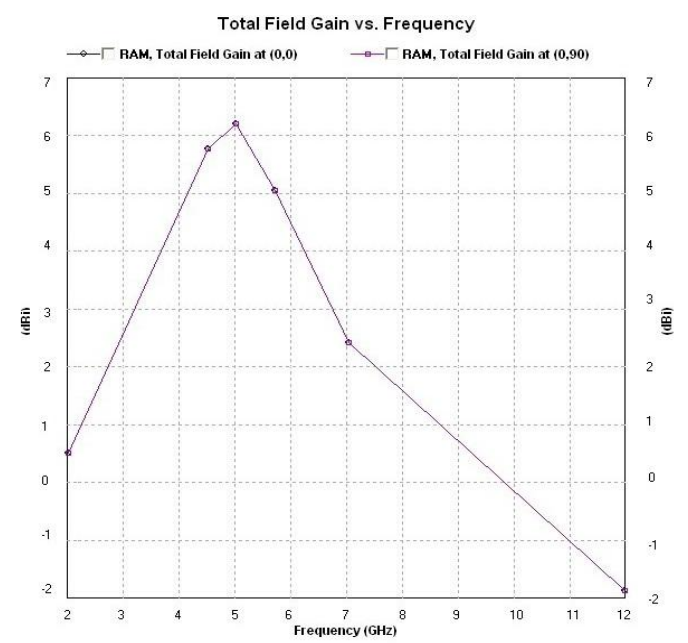

Fig. 5: Gain vs frequency plot

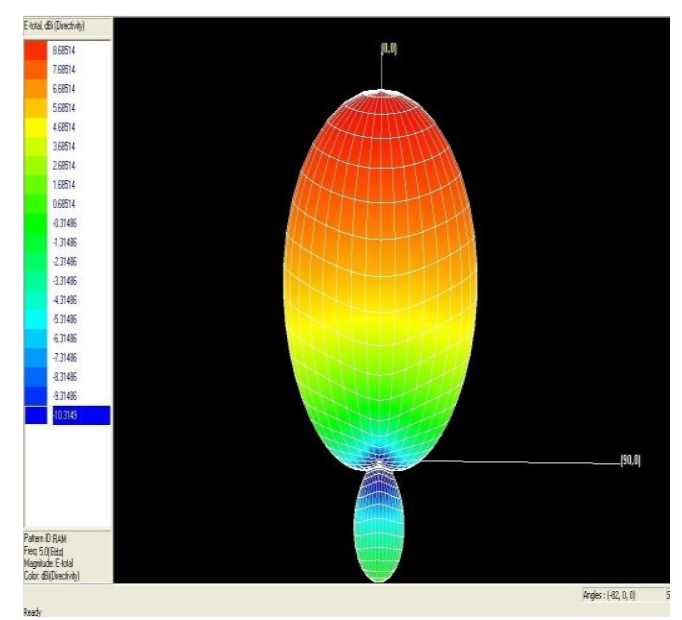

Fig. 6: 3D Radiation Pattern of Patch Antenna 


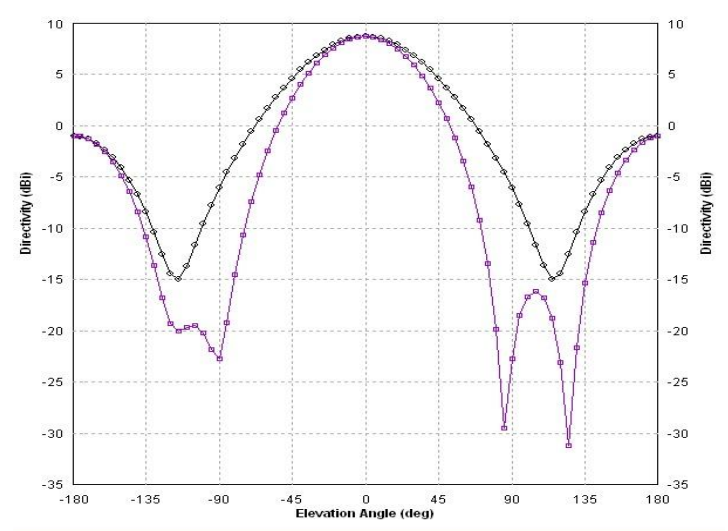

Fig.7: 2D Radiation Pattern of Patch Antenna

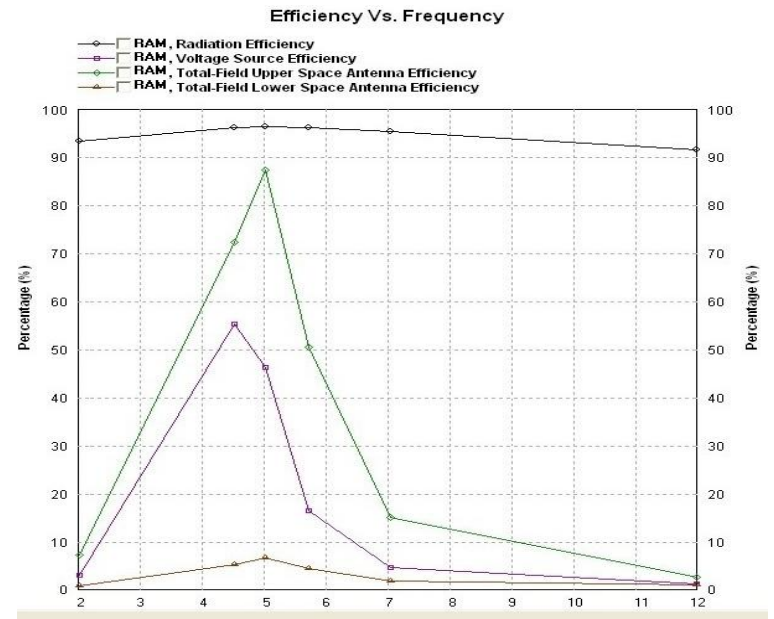

Fig. 8: Efficiency vs frequency plot

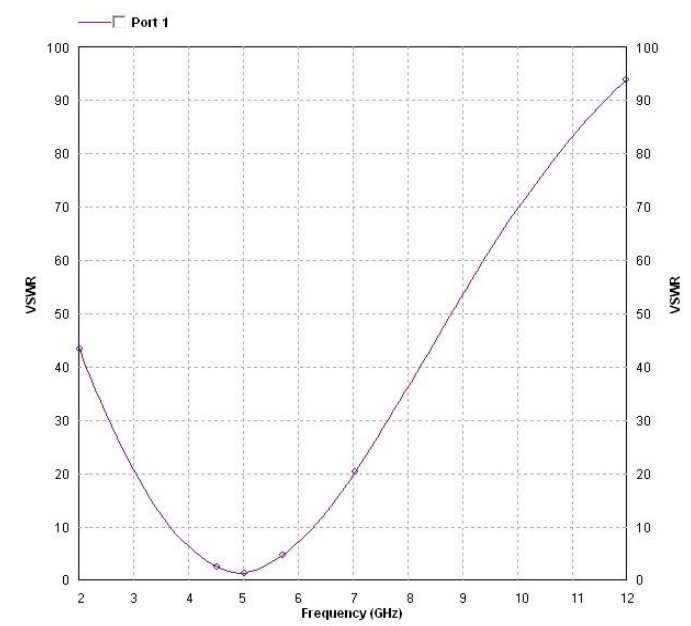

Fig. 9: vswr vs frequency plot 


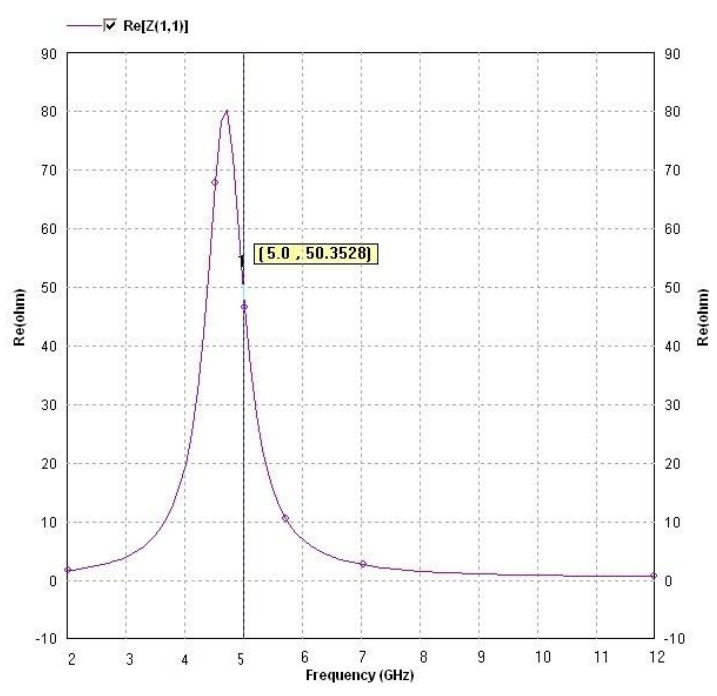

Fig.10 input impedance of patch antenna

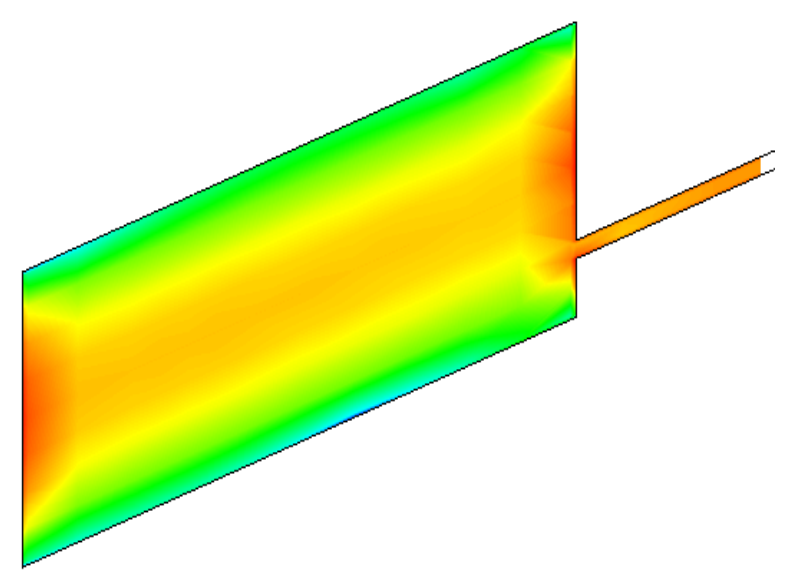

Fig. 11: Average current distribution with colour for the average strength of the current

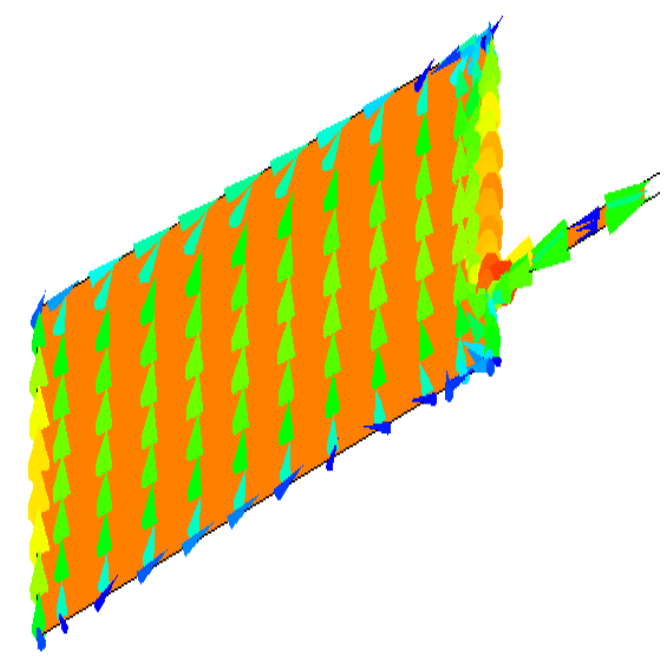

Fig. 12: Vector current distribution with properly adjusted Vector Size of the 3D View window. 


\section{Advantage of Wide Bandwidth for Wind Profiler Applications}

A major problem with any radar - and a wind profiler radar is no exception - is the large required bandwidth. Under the condition that the separation areas between television stations operating in the same channel are large enough to allow the operation of a wind profiler in this channel and in this separation region, the bandwidth issue is no longer a major concern because the profiler could occupy practically the entire width of the TV channel.

- The data rate will be high and therefore the range resolution is high.

- The pulse compression will be smaller with the increment of frequency bandwidth.

- In mobile and broadband communications, it will be very useful.

- Radiolocation, amateur, space operations, amateur-satellite and aeronautical radiolocation services.

\section{Conclusion}

The research motivation of this project is to design rectangular Microstrip patch antenna for atmospheric Wind Profile Radar application which operates in C-band at $5 \mathrm{GHz}$. IE3D electromagnetic simulator is used for design and simulation of patch Antenna. The rectangular patch antenna with 500hms line feed has been designed. The impedance bandwidth of the designed antenna is $20 \mathrm{MHz}$, antenna gain is $6.43 \mathrm{~dB}$, directivity is 8.68 , return loss $-18 \mathrm{~dB}$, the radiation Efficiency at $5 \mathrm{GHz}$ is about $95 \%$ and antenna efficiency is about $85 \%$. From the radiation pattern, it is observed that use of amplitude taper maintained the SLL within the maximum scan angle limit, which is an added advantage for Atmospheric Wind Profile Radar application. The gain and bandwidth of single element patch shows the path of further experiments with arrays of antennas and in the case of dual polarization.

\section{Acknowledgment}

The authors of this paper would like to acknowledge all the corresponding IEEE paper holders and most importantly the publishers of related books and journals which gave immense support and inspiration in preparing this manuscript. Above all, the extreme mental support and source of inspiration from all the family members and friends are widely acknowledged.

\section{References}

[1] Srinivasulu. P, Manas R Padhy, Yasodha. P and NarayanaRao. T, 2010 "Development of UHF wind profiling radar for lower atmospheric research applications". Conference paper at NARL.

[2] Srinivasulu. P, Yasodha. P, Rajendra Prasad. Tand Narayana Reddy. S 2010 "Development of 1280 MHz Active Array RADAR at NARL". Conference Paper at NARL DRAWS-2010.

[3] C.T.P.Song, P.S.Hall and H.G.Shiraz, "Multiband Multiple Ring Monopole Antennas" IEEE Trans. on Antennas and propagation, vol. 51,No.4 pp. 722-729, April. 2003.

[4]. Karaboga, D., K. Guney, S. Sagiroglu, and M. Erler, INeural computation of resonant frequency of electrically thin and thick rectangular microstrip antennas," IEEE Proceedings | Microwaves, Antennas and Propagation, Vol. 146, No. 2, 155\{159, Apr. 1999.

[5]. Mishra, R. K. and A. Patnaik, Neural network-based CAD model for the design of square-patch antennas," IEEE Trans. on Antennas Propagat., Vol. 46, No. 12, 1890\{1891, Dec. 1998.

[6]. Patnaik, A., R. K. Mishra, G. K. Patra, and S. K. Dash, \An arti- cial neural network model for e®ective dielectric constant of microstrip line," IEEE Trans. on Antennas Propagat., Vol. 45, No. 11, 1697, Nov. 1997.

[7] R. G. Voughan. 1988. Two-port higher mode circular microstrip antennas. IEEE, Trans. Antennas Propagat.36(3): 309-321.

[8] D.D.Sandu, O.Avadanei, A.Ioachima, G.Banciua, P.Gasner. Microstrip Patch Antenna with dielectric substrate. Journal Optoelectronics and Advanced Materials Vol. 5, No. 5, 2003.

\section{AUTHORS' INFORMATION}

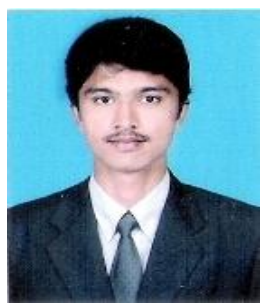

V. HARSHA RAM KEERTHI born in India, 1990, he is currently pursuing M.Tech in Communications \& Radar System Engineering from the Department of Electronics and Communication, K.L University, Vijayawada, A.P, India. Presently he is carrying out his project work on Microstrip Patch Antenna Design from National Atmospheric Research Laboratory (NARL), Gadanki. Department of Space, Govt.of India. He has completed his B.E in Electronics and Communication from Saveetha Engineering College of Electronics, Anna University, Tamilnadu, and India. 


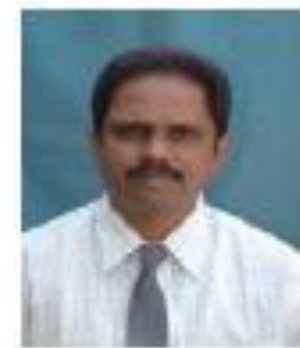

system designing

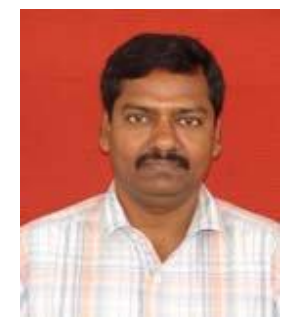

Dr. HABIBULLAH KHAN born in India,1962. He obtained his B.E. from V R Siddhartha Engineering College, Vijayawada during 1980-84. M.E from C.I.T, Coimbatore during 1985-87 and PhD from Andhra University in the area of antennas in the year 2007. He is having more than 20 years of teaching experience and having more than 20 international, national journals/conference papers in his credit. Dr.Habibullah khan presently working as Head of the ECE department at K.L.University .He is Member Board of Studies in ECE and EIE of Acharya Nagarjuna University, Guntur. He is a fellow of I.E.T.E, Member IE, SEMCE and other bodies like ISTE. His research interested areas includes Antenna system designing, microwave engineering, Electromagnetic and RF

Dr. P. SR IN IVASUL U is presently working as Scientist-SF atNational Atmospheric Research Laboratory (NARL). $\mathrm{He}$ is involved in the installation and commissioning of the VHF Indian MST Radar and L-band Boundary Layer Radar at NARL. He has expertise on high power radar transmitters, phased antenna arrays and receivers. Currently he is working on leading active array radar projects in VHF and UHF bands for atmospheric remote sensing application. 